\title{
Afetos e cooperação familiar como coadjuvantes do tratamento de câncer de mama em mulheres
}

\author{
Family affection and cooperation family as adjuvant to the treatment of breast cancer in \\ women
}

\author{
Bianca Beraldi Xavier* \\ Raquel de Matos Lopes Gentilli**
}

\begin{abstract}
Resumo:
Este artigo, produzido na forma de um estudo teórico, tem o objetivo de evidenciar como os afetos relacionados à vida familiar, podem ser mobilizados para o tratamento de câncer de mama e interferir nas expectativas de cura. $\mathrm{O}$ tema se situa no contexto de um tratamento que acarreta mutilações, que produz repercussões psicológicas, sexuais, sociais e econômicas na vida das pacientes. As reflexões aqui desenvolvidas utilizaram pesquisa em livros, documentos do Instituto Nacional de Câncer e do Ministério da Saúde sobre o assunto, dissertações, teses e artigos indexados, acessíveis para consulta na base de dados Scielo. Os resultados dos estudos indicam que, devido à redução na capacidade física e ao adoecimento, também podem ocorrer alterações na vida econômica da família. O tratamento em equipe interdisciplinar contribui para motivar as mulheres a reverterem suas expectativas, além de estimular os próprios familiares a cooperarem no tratamento como um todo. Como conclusão observou-se que o Serviço Social precisa trabalhar na equipe interdisciplinar com o suporte da família e das questões assistenciais e previdenciárias.
\end{abstract}

Palavras-chave: Neoplasia de mama. Equipe Interdisciplinar. Serviço Social. Afetos e cooperação familiar. Atendimento familiar.

\begin{abstract}
:
This article was produced as a theoretical study and aims to show how affections related to family life can be mobilized for the treatment of breast cancer and interfere in the expectations of cure. This issue lies in the context of treatment that causes mutilations and produces psychological, sexual, social and economic consequences in their lives. The reflections developed here have been based on researches in books, documents from National Cancer Institute and Ministry of Health, dissertations, thesis and articles indexed and assessable in Scielo database. The study results indicate that changes in the economic life of the family may also occur due to reduction of physical capacity and illness. The multidisciplinary
\end{abstract}

\footnotetext{
* Assistente Social, Mestre em Políticas Públicas e Desenvolvimento Local da Escola Superior de Ciências da Santa Casa de Misericórdia de Vitória - EMESCAM - ES e Assistente Social do Hospital Santa Rita de Cássia E-mail: biancaberaldi@santarita.org.br.

** Assistente Social, Mestre em Ciências Sociais e Doutora em Serviço Social, ambos pela Pontifícia Universidade Católica de São Paulo. Professora Aposentada da Universidade Federal do Espírito Santo. Professora do Mestrado em Políticas Públicas e Desenvolvimento Local da EMESCAM-ES (2009-2011). Consultora em Serviço Social e Políticas Públicas. E-mail: rgentilli@uol.com.br.
} 
treatment team helps to motivate women to reverse their expectations and stimulate their own families to cooperate in treatment as a whole. In conclusion it was observed that, in that case, the social work must act in the multidisciplinary team with the family support for the patient and in assistance and security issues.

Keywords: Breast neoplasm. Multidisciplinary team. Social work. Family affection and cooperation family. Assistance to family.

\section{Introdução}

Segundo tipo mais frequente no mundo, o câncer de mama é o mais comum entre as mulheres, respondendo por $22 \%$ dos novos casos a cada ano. Se diagnosticado e tratado oportunamente, o prognóstico de cura é considerado relativamente bom. No Brasil, entretanto, as taxas de mortalidade continuam elevadas, muito provavelmente porque a doença ainda tem sido diagnosticada em estádios avançados, enquanto que na população mundial, a sobrevida média após cinco anos é de $61 \%$. Segundo o Instituto Nacional do Câncer, a estimativa é de ocorrerem 52.680 novos casos de câncer de mama somente em 2012.

Duarte e Andrade (2003) discorrem que, como as mamas desempenham um papel fisiológico importante em todas as fases do desenvolvimento feminino, mostrando as transformações do corpo das mulheres desde a puberdade, inevitavelmente provocam associações com a identidade feminina como mulher e como mãe, uma vez que tal associação é decorrente do fato das mamas serem órgãos ligados ao prazer sexual e à função fisiológica de nutriz da mulher. Esse aspecto coloca o câncer de mama como uma neoplasia fortemente associado a fatores subjetivos femininos, além dos demais fatores de risco como a herança genética, fatores ambientais, agentes químicos e radiações.

De acordo com o Instituto Nacional do Câncer (BRASIL, 2006), historicamente, o câncer sempre esteve associado à dor, à morte, à culpa, ao medo e, sobretudo, à estigmatização social. A alta incidência, as consequências psicossociais e as incertezas, quanto à etiologia e ao tratamento, revestem o câncer de forte valor simbólico, sobrecarregado de significados. Neste trabalho são apontadas algumas menções preconceituosas sobre a doença. 
No século XIX e início do século XX, o câncer, além de ser considerado contagioso, era associado à falta de limpeza, sujeira física e moral. No caso das mulheres, o adoecimento era considerado como resultado de pecados e vícios, principalmente os de natureza sexual. A medicina listava diversos elementos da vida vinculados à industrialização como possíveis causas do câncer. Destacavam-se as ideias de que o câncer seria decorrente das vias asfaltadas, das poeiras das ruas, de gazes liberados pelos motores em funcionamento, das chaminés industriais, das geladeiras elétricas e até do uso de sapatos apertados e de saltos altos (XAVIER, 2011).

Os médicos, em suas atitudes moralizadoras e higienistas no Brasil do início do século XX, preconizavam o isolamento e a desinfecção das residências de pacientes mortos de câncer, assim como faziam com os casos de tuberculose e os de sífilis. Associados à pobreza e à sujeira, tais pacientes eram considerados inimigos da sociedade, pois não contribuíam para a produção da riqueza social e ainda oneravam os cofres públicos, os privados e os da filantropia em decorrência dos gastos com os tratamentos. O paciente de câncer já foi considerado uma pessoa irresponsável socialmente por deixar de seguir as regras de higiene, e a doença era tida como um castigo para os impuros pela qual alcançariam a redenção e libertação espiritual (XAVIER, 2011).

Esse contexto torna a história do câncer até os anos 1940 um grande peso a ser carregado principalmente pelas mulheres, pois o adoecimento provocava pudor, vergonha, isolamento e ameaça de terem mutilados seus órgãos sexuais símbolos de feminilidade, como é o caso do câncer de mamas. A partir dos anos 1950, com os avanços dos métodos de diagnósticos e de tratamentos (quimioterapia e radioterapia), ocorreram possibilidades de aumento do número de sobreviventes. Com o acompanhamento prolongado dessas pacientes, evidenciou-se a necessidade de lhes serem proporcionada melhor qualidade de vida. Tal situação também estimulou o estudo das repercussões psicossociais da doença sobre as pacientes, suas famílias e sobre os profissionais de saúde que trabalhavam com oncologia (BRASIL, 2005).

Mas é somente a partir da década de 1970, seguindo o movimento internacional, que as vivências das mulheres mastectomizadas passaram a receber atenção mais acentuada, inclusive provocando repercussões na mídia. Uma importante mudança nas atitudes e procedimentos de profissionais que passam a orientar e estimular um novo e 
mais ativo papel das pacientes em seus respectivos tratamentos. É nesse período que se começa a esperar das pacientes uma atitude nova e mais ativa em relação ao câncer de mama, inclusive como fator coadjuvante do tratamento (BRASIL, 2006).

Enfrentar o câncer de mama ganha nova perspectiva ideológica. Deixa de se limitar a se esperar a morte certa e as pacientes são estimuladas a lutarem pela sobrevivência. Esse outro ponto de vista estimula as pacientes ao conhecimento do próprio corpo e são iniciados os tratamentos aos sofrimentos subjetivos. Também se valoriza o acompanhamento e o suporte social e familiar as pacientes e familiares e estimulados depoimentos sobre a experiência pessoal com a doença, exposições e histórias de vida das pacientes, visando o enfrentamento a estigmas e preconceitos anteriores. Essas mudanças nos significados e nas formas de enfrentamento do câncer acompanharam o desenvolvimento de novas teorias e novos tratamentos, que resultaram em terapêuticas mais eficientes e equipe de especialistas mais sólidas com oncologistas, cirurgiões, enfermeiros, assistentes sociais, psicólogos, nutricionistas, entre outros.

Nesse início do século XXI, apesar de todo avanço alcançado nas pesquisas sobre os diversos fatores implicados nos diagnósticos e nos tratamentos, o câncer de mama permanece ainda como uma doença de causa obscura, cujo tratamento não é totalmente eficaz.

Segundo Duarte e Andrade (2003), os fatores etiológicos das diversas formas de manifestação do câncer são variados e podem ser internos ou externos ao organismo, estando ambos inter-relacionados. As causas internas são, na maioria das vezes, geneticamente predeterminadas e estão ligadas à capacidade do organismo de se defender das agressões externas. As causas externas se relacionam ao meio ambiente e aos hábitos ou costumes próprios de um espaço social e cultural. Esses fatores podem interagir de várias formas, aumentando ou diminuindo a probabilidade de ocorrerem transformações malignas nas células normais.

Segundo Ferrari e Herzberg (1997), estima-se que até 70\% dos casos de câncer podem ser evitados com a prevenção de exposição aos fatores de risco ambientais como hábito de fumar, modificações na dieta, prevenção de doenças sexualmente transmissíveis, controle de exposição a agentes químicos, a radiações ionizantes e a raiosultravioletas. 
Como o câncer de mama é uma doença predominantemente feminina, complexa e com variações individuais e não existe uma única conduta aceita para seu tratamento e sua prevenção, geralmente enfatiza-se a realização periódica de mamografias como conduta preventiva. Os esquemas de tratamento decorrem das variações de diagnóstico, da histologia, das condições emocionais, nutricionais e sociais da paciente, de sua idade, grau de progressão da doença e dos protocolos adotados pelos oncologistas e cirurgiões (NETTINA, 2003).

O câncer de mama provoca muita preocupação entre as mulheres, pois apesar de todos os avanços da medicina, sua mortalidade ainda se apresenta acentuada e a mastectomia (retirada total da mama) possui um caráter inegavelmente mutilatório, cuja agressividade parece ferir a suscetibilidade das mulheres, mesmo com os recentes esforços para a realização de cirurgias plásticas corretivas.

\section{As Políticas Públicas de Atenção Oncológica no Brasil}

No Brasil, a abordagem do câncer como problema de saúde a ser enfrentado pelo Estado se deu somente a partir dos anos 1920, influenciada por políticas anticâncer positivas nos países desenvolvidos (principalmente França e Alemanha) e por pesquisadores como Eduardo Rabello, Mario Kroeff e Sérgio Barros de Azevedo, que começaram a pensar o câncer como um processo sanitário a ser gerenciado pelo Estado (TEIXEIRA; FONSECA, 2007).

Somente no início da década de 1930 , no Governo Provisório, é que viriam os primeiros investimentos na construção de um aparato hospitalar para tratamento e estudo do câncer. Em 1937, Getúlio Vargas assina o Decreto-Lei no 378, criando o Centro de Cancerologia, no Serviço de Assistência Hospitalar do Distrito Federal, no Rio de Janeiro, embrião do Instituto Nacional de Câncer, que seria inaugurado no ano seguinte pelo próprio Getúlio Vargas e Mario Kroeff. Em 1941, o Serviço Nacional de Câncer (SNC) foi destinado a orientar e a controlar as campanhas de prevenção e de tratamento de câncer em todo país (TEIXEIRA; FONSECA, 2007).

O Brasil sediou, em 1954, o VI Congresso Internacional de Câncer, em São Paulo, organizado pela União Internacional Contra o Câncer (UICC). Neste evento, o câncer foi considerado um problema de saúde pública, e a ideia de controlá-lo deu origem a novas 
adesões. A nova perspectiva recebeu outros significados como as orientações sobre prevenção, diagnóstico e tratamento do problema e meios práticos, capazes de educar a população. Visava-se influenciar na expectativa de redução da mortalidade (TEIXEIRA; FONSECA, 2007).

Em 1957, foi inaugurado um hospital com a dupla função de assistência e estudo no Rio de Janeiro. Trata-se do atual Instituto Nacional do Câncer (INCA), que de sede do serviço criado anteriormente, transformou-se na principal referência do assunto no Brasil. A partir de então, os esforços de unificação das ações de controle do câncer resultaram em 1967, na institucionalização da Campanha Nacional de Combate ao Câncer (BRASIL, 2006).

Percebendo-se que a mortalidade em decorrência dos cânceres continuava elevada, nos anos 1980, foi criado o Programa de Oncologia (Pro-Onco), com objetivo de aprimorar o controle da doença (TEIXEIRA; FONSECA, 2007).

Na década de 1990, com o processo de estruturação do Sistema Único de Saúde (SUS), o INCA assume o papel diretivo das políticas de controle do câncer no país. Em 1998, surgiu o Programa Nacional de Controle do Câncer de Colo de Útero, e em 2000 o Programa Viva Mulher, consolidando as diretrizes técnicas para o controle dos principais cânceres que acometem as mulheres no Brasil (BRASIL, 2004). O esforço para consolidar as ações nacionais de controle do câncer culminou, no final de 2005, com o lançamento da Portaria 2439/GM que estabeleceu a Política Nacional de Atenção Oncológica (PNAO). A PNAO consiste numa forma inovadora e integrada do SUS de tratar a questão do câncer no Brasil, com ações que vão desde a promoção da saúde até os cuidados paliativos, na fase terminal da doença (BRASIL, 2005).

Transforma-se, assim, em exemplo da atenção do Estado a um problema de saúde de grande incidência e alto índice de mortalidade, reconhecido como importante agravo epidemiológico. Nesse sentido, a Política Nacional de Atenção Oncológica desenha quatro estratégias complementares: 1) estabelecimento, em âmbito nacional, de ações de prevenção de câncer, visando a promoção à saúde; 2) detecção precoce de cânceres passíveis de intervenção precoce; 3) consolidação e expansão dos serviços de assistência oncológica, em todo país, de forma integrada; e 4) promoção de qualificação de recursos humanos e pesquisas, visando a qualidade dos serviços (BRASIL, 2005). 
A novidade desta política está na ênfase à prevenção, promoção e na conscientização da população quanto aos fatores de risco de câncer, tendo em vista levar à redução da incidência do adoecimento. Apesar disto, a redução efetiva da mortalidade depende muito da detecção precoce e acesso ao tratamento adequado e a tempo hábil.

A associação destas medidas, a serem consideradas na perspectiva da integralidade, constitui o grande mérito da saúde ter se tornado um objeto de cuidados em todos seus aspectos, sobretudo quando os agravos se tratam de doenças complexas como as que se manifestam nas diversas formas de câncer.

\section{O adoecimento e a dinâmica Interativa nas relações familiares}

A descoberta do câncer de mama constitui-se um choque para a mulher, tendo em vista a representação social que ainda se faz do câncer como morte certa, fato que ainda se confirma, infelizmente, em muitos casos. As expectativas das pacientes são impregnadas de medos, fantasias e temores estigmatizantes desde as primeiras indagações diagnósticas. Muitas informações novas precisam ainda ser processadas e o momento da descoberta transforma-se num período ainda considerado de muita vulnerabilidade para a paciente.

Segundo Nettina (2003), os fatores da doença são insidiosos. Um tumor indolor, que se desenvolve na mama e que pode ser móvel contribui para que poucas mulheres tomem consciência da doença. Raras vezes elas entram em contato com o câncer por meio de um desconforto bem localizado, que pode levar a uma queimação, ardência ou dor. Pode-se destacar que, em alguns casos, as mulheres não apresentam sintomas e não possuem tumor palpável.

Essa doença misteriosa estabelece socialmente uma relação dependente de muitos saberes profissionais. Entretanto, alguns discursos atuais, advindos de profissionais, cientistas, pacientes, familiares ou da coletividade em geral, ainda se configuram como limitadores das possibilidades terapêuticas, na medida em que veem as mulheres apenas como pessoas doentes, dependentes de cuidados e receptoras passivas das prescrições e de discursos elaborados por autoridades científicas, geralmente médicas.

Poucas são as possibilidades da produção de um discurso contra-hegemônico, que aposte no protagonismo da mulher e no estabelecimento de outras práticas coadjuvantes 
no processo de cura. Encontram-se, até mesmo entre pacientes que sobreviveram à doença e que realizaram tratamento com uma equipe multiprofissional, uma tendência de reproduzir os discursos centrados na cura pela prática médica; desconsiderando seus próprios protagonismos ou mesmos os grupos de apoio, as terapias psicológicas e os suporte sociais.

Comin, Santos e Souza (2009) já haviam registrado que tal fenômeno já fora identificado em estudos anteriores, e, de certa forma, reproduzidos, inclusive, em outras áreas de saber. As narrativas são frequentemente influenciadas por esse modelo hegemônico, que é fortemente relacionado ao adoecimento e à doença como um evento meramente orgânico, não valorizando as estratégias de enfrentamento e as possibilidades transformadoras que o adoecer comporta.

Outro aspecto importante a ser observado ocorre logo após o impacto inicial do diagnóstico. Nesse momento emerge a dificuldade das mulheres assimilarem a realidade do adoecimento. Elas sofrem muito com a perspectiva de abandono afetivo da família, sobretudo dos filhos e companheiros, apesar de se constatar que existem hoje muitas possibilidades de tratamentos a serem realizados, o que vem transformando o câncer de mama numa doença crônica. Temem abandonar e serem abandonadas. Existem pacientes que ainda ficam apáticas e passivas em face do diagnóstico. Muitas, porém, desejam não ser meras expectadoras do processo, mas sim protagonistas efetivas do tratamento. Essa realidade, entretanto, é bem diferente do que ocorria há anos atrás, quando as mulheres entravam nos centros cirúrgicos e saiam sem as mamas, sem nenhuma informação sobre o que lhes aconteceria.

O avanço na socialização das informações sobre saúde e doença, a postura dos médicos em dialogarem com as pacientes, assim como a abordagem interdisciplinar de integrar o tratamento físico e emocional ao suporte social têm contribuído significativamente para que sejam realizadas modificações importantes na forma de condução do tratamento em relação à mulher adoecida e à própria família.

Observa-se que a mulher necessita de certo tempo para assimilar toda a complexidade de seu adoecimento, bem como as repercussões deste sobre a dinâmica familiar. Não raro, ela é responsável por muitos encargos na família, e o enfrentamento de uma doença com tantos significados lhe exige muito esforço. Este é um momento em 
que necessita se sentir apoiada e, às vezes, o tratamento adequado pode ficar comprometido em decorrência das diversas pressões que ocorrem em consequência de fatores relacionados à organização da vida familiar de natureza psicológica, social e econômica.

Franco (2008) destaca que toda família terá sua vida alterada, de maneira mais ou menos significativa, ao longo de qualquer doença potencialmente fatal de um de seus membros. Para ele, a família vista mais das questões interativas que biológicas consiste um poderoso círculo no qual as relações de todo o grupo tornam-se mais intensas, tanto com o doente, quanto com a doença; ocorrendo troca de informações e sentimentos que afetam ligações e vínculos pessoais, recíprocos e obrigatórios.

No tratamento do câncer de mama é comum a utilização do raciocínio de que o câncer é uma doença que afeta não só a paciente, mas também suas relações mais próximas. Podem ser incluídas nesse círculo familiar todas as pessoas com as quais a paciente possui ligação afetiva como amigos, parentes e até ex-maridos que, para fins de tratamento, possam se envolver no processo terapêutico da paciente. Nesse caso, o importante é identificar quem é a família (afetivamente falando) daquela paciente; ou seja, quais as pessoas que ela considera como sua família e que deseja a presença.

No período do diagnóstico, os familiares e a paciente são informados sobre a doença e o que ela afetará a todos. Apesar desse momento não acabar com as incertezas - pois novas situações relativas ao tratamento e prognóstico poderão ainda ocorrer -, este tende reduzir um pouco o medo da morte e da dor.

Cada paciente reage de um jeito. Existem situações em que algumas não querem compartilhar o diagnóstico com a família, assim como existem familiares que preferem manter a paciente na ignorância, não querendo informá-la do diagnóstico. Tais situações podem dificultar a comunicação e o apoio entre os diferentes familiares e a paciente, podendo causar posteriormente raiva, ressentimento, culpa, sendo necessária uma avaliação dessas decisões e suas consequências (FRANCO, 2008).

O fato de as mulheres, em geral, possuírem responsabilidades pelo cuidado da família inteira, apesar de fragilizadas, as leva à tendência a mostrarem que ainda se encontram na função de cuidadoras. Demonstram preocupações com os filhos e esposos, contribuindo muitas vezes, ainda que doentes, para o equilíbrio da família. Isso mostra 
uma faceta do papel da mulher na dinâmica e no funcionamento familiar, mediado ainda por uma antiga e arraigada visão de que o homem não sabe se cuidar e que precisa ser cuidado.

$\mathrm{Na}$ verdade todos os membros da família necessitam de cuidados profissionais, pois todos estão abalados, mas não se pode permitir que esta mulher seja sobrecarregada. Nesse momento, é ela quem está na posição mais vulnerável do processo. É seu o corpo e a sua existência que estão seriamente ameaçados.

Sobre a evolução da doença, Rolland (2001) diferenciou três fases: a) a fase da crise; b) a fase crônica; c) a fase avançada. Cada uma destas fases tem suas próprias exigências e requerem determinadas atitudes ou mudanças por parte dos familiares. A fase de crise compreende o período sintomático, dos exames para confirmar o diagnóstico. A família experimenta sentimento de choque, incerteza e uma significativa manifestação de emoções, em que a tendência é a união para atender às necessidades imediatas, para elaborar a aceitação da doença e preparar seus enfrentamentos.

Nessa fase pode ocorrer uma conspiração do silêncio que provoca efeitos negativos nas relações familiares e na sensação de bem-estar dos seus membros; além de, em alguns casos, ocorrer a presença da tristeza pela perda de certa forma de identidade familiar.

Os familiares precisam aprender a lidar com a dor e com as limitações ligadas à doença, a lidarem com o hospital e a manterem bom relacionamento com a equipe médica. Nesse momento, é fundamental buscar uma atitude de aceitação em face às mudanças e uma reorganização das relações familiares. Perante a crise, é necessário que sejam estabelecidos objetivos para o futuro.

A fase crônica se caracteriza pela lamentação da família pela perda da saúde do membro doente, pela redefinição de papéis e criação de um suporte para suprir as necessidades da paciente e para acolher as novas demandas da família.

À medida que a doença vai evoluindo, maior pode ser o número de familiares que experimentem ou manifestem sentimentos de raiva, medo, ciúmes e outras carências, que pode provocar algum tipo de adoecimento em outros membros da família. Tais sentimentos também podem aparecer em caso de reincidência, motivados pela ausência 
da cura da paciente, conforme pode ser observar em pesquisas posteriores como em Biffi, R.; Mamede, M.V. (2010), por exemplo.

Na fase avançada da doença, ou melhor, quando não existe mais a possibilidade terapêutica de cura do câncer, a família precisa aprender a lidar com a eminência da morte; com os afetos associados à separação do familiar doente; com a gravidade da doença que leva a paciente ao leito e com as mudanças estruturais e eventualmente financeiras da família.

Simonton (1991) chama a atenção para o fato das mudanças serem os principais fatores estressantes com os quais o ser humano tem que lidar. No caso dos cânceres, estes já ocorrem a partir do diagnóstico, das informações que precisam ser reunidas e das decisões que necessitam ser tomadas para o tratamento.

O adoecimento de câncer, em um membro da família, sempre provoca uma crise. A situação provocada já na fase diagnóstica costuma alterar os modos de relacionamento e de interdependência numa mesma família, colaborando, inclusive, para acentuar os conflitos internos, previamente existentes. Por outro lado, apesar de toda essa dramaticidade, ocorre também o contrário: a família repensa seus valores, busca restabelecer seus vínculos perdidos e até resolva antigos conflitos.

Em face dessa complexidade no cenário familiar, as pessoas são chamadas a tentarem encontrar maneiras de melhorar a qualidade da convivência de forma gradativa, pois, sendo esta uma doença de longa duração, o mais aconselhável é que não se faça mudanças drásticas imediatamente. Uma estratégia que ajuda a família a atravessar uma crise longa como a desencadeada pelo câncer, e que ajuda a lidar com ansiedade, é o aumento do contato físico, da presença e do carinho entre seus membros.

Ribeiro (1994) considera que o surgimento do câncer em qualquer família é sempre uma catástrofe, no entanto, se bem orientada, a família poderá extrair desta experiência seu crescimento como grupo social. Para o autor, se uma família permanecer unida, tendo oportunidade de manifestar suas emoções e sentimentos de perda e tristeza, a experiência pode vir a propiciar mudanças importantes nos padrões de relacionamento familiar, na própria maneira de enfrentar a vida e no amadurecimento emocional de todos. 
É quase senso comum considerar que as difíceis condições de vida sempre predispõem as pessoas a adoecimentos diversos. No caso do adoecimento por câncer de mamas em mulheres provedoras e cuidadoras de suas famílias - que desempenham papel estratégico na aglutinação e manutenção do agrupamento familiar -, essa situação se agrava ainda mais. O risco do adoecimento em outros membros da família é muito frequente. Desse ponto de vista, a questão social e afetiva nessas famílias é sempre muito dramática, pois as pacientes de câncer necessitam do apoio da família e de sua ajuda material e emocional, considerados como fundamentais na continuidade do tratamento.

Para Venâncio (2004), esse apoio contribui, inclusive, na prevenção da depressão e da ansiedade tão comuns no cotidiano dessas pacientes. $\mathrm{O}$ autor acredita ainda que $\mathrm{O}$ suporte familiar constitui-se um apoio fundamental tanto à recuperação das pacientes quanto ao trabalho da equipe.

Analisando os tipos de suporte possíveis, Rodrigues (2008) se refere a três: 1) o suporte emocional, manifesto nos afetos dos familiares, dos amigos, da vida conjugal e sexual; 2) o suporte material, envolvendo colaboração nas atividades domésticas; e 3) o suporte de pertencimento num grupo de ajuda mútua, que pode ser viabilizado pela equipe de saúde do hospital.

Macieira e Liberato (2008) chamam a atenção para o suporte de pertencimento que um grupo de apoio oferece à recuperação das pacientes. Nas experiências dessa natureza, é comum observar que o enfrentamento depende das características individuais, significado e importância que atribuem à doença. Essas variações dependem do jeito de cada uma, sua história de vida, do contexto sociocultural, familiar, oportunizando o que Messa (2003) considera como a capacidade das pacientes e familiares de utilizarem recursos de enfrentamento e aprendizagem emocional.

Franco (2008) salienta ainda que o adoecimento grave de uma pessoa ameaça e atinge os projetos familiares, que poderão vir a ser mudados ou adiados. Novas responsabilidades ocorrerão sobre determinados membros em decorrência da pressão do tempo e de adoecimentos de outras pessoas vulneráveis da família em decorrência do estresse e das mudanças.

Macieira e Liberato (2008) assinalam ainda, a partir de relato de sobreviventes, que as crenças religiosas e a fé podem exercer um papel positivo nas estratégias emocionais 
de enfrentamento do sofrimento. Ambas auxiliam no senso de disciplina do tratamento e na promoção de esperanças, que possibilitarão melhorar a adesão ao tratamento. Tal fato é percebido pela intensificação de idas às igrejas, de orações e outras manifestações religiosas que dão suporte emocional e contribuem ainda na agregação dos envolvidos no processo de tratamento.

Os problemas das mulheres que sofreram mastectomia são bem mais abrangentes que os aportes que podem ser oferecidos pelos profissionais da área da saúde, sobretudo para as pacientes com maiores dificuldades econômicas. Existe necessidade de intervenção de profissionais de formações diversas e até de reeducação para a vida. Nesse sentido, o acompanhamento da paciente é fundamental. A atenção ainda se volta às vivências da prática cotidiana e aos vínculos familiares e as ações coletivas e comunitárias ainda são insipientes. Com relação à família, o foco está na relação entre mãe e filhos e na relação do casal, quando há.

Dos filhos, busca-se um reforço dos afetos, geralmente, favorecido pela maternidade. Dos parceiros, busca-se, sobretudo, o reforço do vínculo para se evitar os abandonos sexuais e a rejeição do corpo mutilado (de mulheres não mais "inteiras"), o que agrava muito os aspectos emocionais.

Por fim, é importante registrar que a participação em grupos de reabilitação é muito positiva, principalmente se os grupos buscarem nessa convivência trabalhar as limitações que a doença traz e a capacidade de superação destas, reafirmando a condição de um ser inteiro.

Os grupos de apoio mostram-se importantes na reabilitação das pacientes, pois o histórico em comum, que é a vivência do câncer e da retirada da mama ou de parte dela devido à doença, funciona como um ponto de convergência. São estabelecidos vínculos de identificação entre as mulheres na perspectiva de superação da doença. No grupo, discutem questões relacionadas ao câncer e com a vida após o tratamento, realidade que dificilmente poderiam ser compartilhada nos outros espaços de convívio.

Comin, Santos e Souza (2009) consideram que as ideias produzidas no âmbito do grupo podem nutrir o sentimento de confiança nas possibilidades de tratamento e de erradicação da doença maligna, ressoando também intensamente em outros espaços sociais nos quais as pacientes convivem. O grupo representa o microcosmo no qual se 
dão as interações e as falas das protagonistas do processo de negociação com a nova vida e com os novos significados desta experiência humana.

\section{O atendimento do Serviço Social na equipe interdisciplinar}

A situação de saúde envolve diversos aspectos da vida como meio ambiente, alimentação, condições de trabalho e renda, moradia, lazer e qualidade de vida nas relações sociais e socioafetivas. No caso dos cânceres, variáveis como raça, etnia e pobreza realçam ainda mais o papel das desigualdades sociais na emergência e evolução dos adoecimentos. No caso das mulheres, para além das questões acima referidas, as condições de saúde podem ser agravadas pelas discriminações existentes nas relações de gênero no trabalho e na sobrecarga das responsabilidades no trabalho doméstico (XAVIER, 2011).

Esses fatores motivaram o Ministério da Saúde (BRASIL, 2009) a considerar o enfoque de gênero como necessário à organização da atenção à saúde da mulher; determinando não só a condição de integralidade na promoção da saúde, mas também do tratamento de doenças que acometem mulheres, como os cânceres. A Organização Mundial da Saúde (2008) orienta também que no tratamento oncológico seja feito com acompanhamento e controle dos sintomas já a partir do diagnóstico e ao longo de todo o processo de tratamento.

Por envolver múltiplos aspectos, fica clara a importância da equipe interdisciplinar no período de tratamento, buscando trazer qualidade de vida para a paciente e também para seus familiares, atentando para as necessidades físicas, emocionais, psicológicas e sociais, realizadas de forma contínua e dinâmica (GUARINGUE, 2010).

Atualmente em oncologia, já não se concebe o atendimento fragmentado devido à variedade de sintomas existentes, formas de manifestação, órgãos atingidos, complexidade da etiologia e variabilidade na evolução da doença. Tais fatores têm levado a uma política de atendimento em equipe interdisciplinar, prestando assistência às demandas presentes em todo o processo.

Nesse sentido, o diálogo entre os profissionais promove a integralidade que não pode ser considerada apenas como um bom exercício da biomedicina, mas como uma 
prática necessária a todos os profissionais diretamente envolvidos nos cuidados em saúde, conforme preconizado pelo SUS.

O olhar ampliado sobre o conjunto de necessidades das usuárias, bem como a forma como elas procuram resolvê-las, demonstram a necessidade das diversas práticas profissionais estarem implicadas nessa dimensão de integralidade (ALMEIDA, 2009)

Um fator que merece consideração positiva se deve à luta pela diminuição do tempo gasto entre o diagnóstico e a realização da cirurgia e tratamentos adjuvantes. Entre um e outro deve decorrer em torno de um a três meses, conforme vem sendo defendido pela Sociedade Brasileira de Mastologia e pela Federação Brasileira de Entidades Filantrópicas da Saúde da Mama (ONCOGUIA, 2011; FEMAMA, 2012).

O aspecto negativo mais relevante ocorre entre a descoberta do câncer na atenção primária e o grande tempo de espera na marcação das consultas com especialistas e no acesso aos procedimentos da alta complexidade: encaminhamento aos hospitais de referência para realização dos procedimentos como a cirurgia e outros específicos. Estes são os momentos de grande fragilidade na estrutura de acesso aos serviços, em que a resolubilidade nos atendimentos tem ficado comprometida.

Várias constatações desta realidade vêm evidenciando que o agravamento do câncer é influenciado por fatores clínicos, socioeconômicos e também pela disponibilidade e qualidade do cuidado ofertado (BRITO; PORTELA; VASCONCELLOS, 2009).

Esta fragmentação entre os níveis de assistência têm ampliado o desafio do SUS no cumprimento do princípio da integralidade, cujos gargalos de gestão ainda comprometem a atenção integral (XAVIER; GENTILLI, 2010).

É comum a percepção de que a equipe interdisciplinar se restringe aos profissionais com os quais a paciente desenvolve maior empatia, com destaque para o médico, considerado o profissional da cura, até por existirem descompassos efetivos nos atendimentos.

Apesar da atenção à saúde ter se tornado interdisciplinar, o médico ainda possui o poder e a liderança do tratamento em oncologia; poder esse conferido e valorizado socialmente. Ao médico é atribuído o poder de comunicar a cura e o de ser o emissário da boa ou da má notícia. Por isso, sua figura é sempre investida de elevadas expectativas. 
Spink (2003) lembra que esse valor conferido ao médico é algo construído e fortemente reforçado socialmente, em que se reforça o saber do médico como legítimo detentor do saber científico, como sinônimo de verdade e de conhecimento inquestionável.

A dinâmica da relação médico-paciente pode vir a favorecer ou dificultar o tratamento das determinantes psicossociais, econômicas e outras. Em face dessa realidade, a intervenção interdisciplinar torna-se um constante desafio a ser enfrentado em decorrência das múltiplas questões envolvidas no tratamento, por mais que a sociedade demande os cuidados de um médico mítico.

Em relação à prática profissional do Serviço Social, vale destacar que desde sua origem, o assistente social sempre foi um agente profissional que buscou a participação dos usuários nos seus serviços, trabalhou na informação sobre os aspectos da doença e na construção conjunta no enfrentamento de tratamentos. Tradicionalmente esteve presente nas instituições de saúde como as que realizavam cirurgias, sobretudo na orientação e preparação de pacientes para mutilações (GENTILLI, 2006), como é o caso das cirurgias de câncer de mama.

A atuação do assistente social no atendimento à paciente com câncer de mama ocorre desde o primeiro momento que a paciente chega ao serviço. $\mathrm{O}$ assistente social acolhe suas demandas e presta-lhe informações claras sobre o tratamento e sobre a importância dela se colocar no processo terapêutico como protagonista. Possibilita também uma reflexão sobre seu comprometimento com o processo de cura, com seu corpo e com sua vida (XAVIER, 2011).

A atenção do Serviço Social se realiza por meio de instrumentos técnico-operativos bem singelos, porém eficientes e fartamente utilizados para atendimento individual e grupal na profissão. Por meio destes instrumentos se estabelece uma aproximação maior à realidade socioeconômica e socioafetiva das pacientes, identificando as necessidades que estas possuem no momento do adoecimento. Com isso, o Serviço Social viabiliza o acolhimento dos sofrimentos em relação às questões que estão relacionadas à vida social, assim como daqueles que afetam a família e demais relações socioafetivas das mulheres em adoecimento. 
Com estes contatos, os profissionais podem realizar encaminhamentos para a rede de serviços sociais existentes, para os tratamentos imprescindíveis a cada caso, além de procurar envolver pessoas significativas para a paciente no processo de cura.

Existe hoje um avanço nas abordagens terapêuticas, inclusive, dos oncologistas, em que se evidencia uma nova postura que implica conceber a inclusão dos pacientes nos processos de tratamento, convocando-os a serem menos expectadores e mais protagonistas dos processos terapêuticos. Supera-se, assim, a perspectiva das abordagens mais tradicionais que tratavam o paciente como um corpo que não the pertencia, mais como meros procedimentos terapêuticos.

Tal ponto de vista, que persegue uma perspectiva de atendimento de forma integral, coaduna-se com a perspectiva profissional do Serviço Social, cujo compromisso vem claramente assumido na Lei 8662/93, que regulamenta a profissão e em seu Código de Ética Profissional, claramente identificados com o reconhecimento e com a garantia dos direitos sociais dos usuários dos programas públicos de políticas sociais destinados à população.

$\mathrm{Na}$ equipe interdisciplinar, o assistente social também tem respondido pela importante tarefa de defender a qualidade dos serviços e a abordagem intersetorial dos atendimentos a partir da perspectiva da intersetorialidade das políticas públicas.

O Serviço Social compreende bem estes aspectos em decorrência de sua inserção nas políticas sociais que, além de habilitar o profissional para atuar na interface da gestão dos diferentes setores das políticas públicas, considera que a fragmentação das ações no atendimento às demandas dos usuários é algo muito prejudicial aos pacientes e à gestão dos serviços. Gentilli (2006) considera que, na prática, a atuação do assistente social persegue os objetivos de viabilizar o acesso aos direitos da população e ao exercício da cidadania.

A importância do Serviço Social nesse contexto social consiste em compreender a paciente mastectomizada como mulher, mãe, esposa e trabalhadora, que necessita ser acolhida em sua integralidade. É nesse sentido que se entende que os condicionantes socioafetivos podem desempenhar um papel estratégico para a recuperação da mulher acometida pelo câncer de mama. 
A atuação do Serviço Social em oncologia tornou-se um fazer bastante amplo, levando o profissional também a desenvolver ações na prevenção, na assistência e nos cuidados paliativos, junto aos pacientes, familiares e amigos mais próximos, incentivandoos à participação de todos no processo de recuperação da saúde da paciente, tomando-os na perspectiva de cidadãos, que possuem direitos a serem respeitados.

A dificuldade no acesso aos serviços especializados não fere apenas o direito do cidadão à assistência, mas compromete também o princípio de integralidade do SUS, sobretudo para as pacientes com menor poder aquisitivo. Neste sentido, recomenda-se que os assistentes sociais desenvolvam ações para democratizar as informações e garantir o acesso aos serviços oferecidos e à sua resolubilidade em face das situações sociais que interferem no processo saúde-doença; utilizando-se para tanto dos recursos institucionais e comunitários que permeiam sua prática.

As dificuldades da acessibilidade já aparecera nas observações de Milbrath et al. (2009) ao analisar alguns fatores implicados na acessibilidade. Para os autores, os aspectos são muito mais abrangentes que a mera disponibilidade de recursos num determinado momento e lugar. Dependem também das peculiaridades das organizações, da gestão dos serviços e da forma como se compreende o processo como um todo.

Pode-se observar que o simples atraso no acolhimento a uma demanda pode decorrer de fatores externos à lógica dos tratamentos em si, colocando em risco a saúde das pacientes, pois a demora pode desmotivá-las, comprometendo o seguimento adequado do tratamento.

Apesar disto, estratégias importantes no processo de gestão dos serviços públicos podem ser desenvolvidas, como o intercâmbio, a articulação de parcerias e o estabelecimento de protocolos entre os diversos níveis de atenção e serviços com o Programa Saúde da Família (PSF), podendo avançar muito no atendimento da paciente em seu domicílio.

Outra parceria importante pode decorrer da intersetorialidade com os Centros de Referência da Assistência Social (CRAS), a partir dos quais, em cada território, com seus profissionais especializados em atenção psicossocial e agentes sociais poderiam ser mobilizados para ações de suporte às pacientes desde o diagnóstico. A realização de 
ações no sentido da transversalidade das políticas sociais é necessária para a construção de um atendimento mais racional e numa perspectiva de totalidade.

Hoje já que existe um acúmulo teórico nesta direção tanto nos debates da política de saúde, quanto nos da assistência social. Apesar da realidade ainda mostrar ações pontuais e paralelas, sem que os compromissos políticos viabilizem ações e parcerias efetivas entre as duas áreas, a transversalidade seria uma importante medida para uma atenção menos fragmentada.

Outro aspecto que se tem observado no cotidiano profissional é a ética do cuidado, do acolhimento, do vínculo, do atendimento humanizado e de responsabilização dos profissionais. Esta perspectiva ética pode contribuir para a um prognóstico mais positivo em direção à cura; contornar as dificuldades de articulação entre os diferentes níveis de atenção (na saúde) e de articulação intersetorial entre as duas políticas e reduzir os elevados índices de diagnóstico tardio e mortalidade pela doença (XAVIER, 2011).

\section{Considerações finais}

Apesar do câncer de mama ser bastante disseminado, revela-se ainda de grande importância o aprofundamento de estudos em suas diversas dimensões, devido ao risco que este significa para a saúde humana no mundo contemporâneo. A detecção precoce e os índices epidemiológicos ainda continuam com pouca alteração e a cirurgia e os demais tratamentos associados ainda tem sido procedimentos muito utilizados, apesar de serem invasivos e dolorosos e causarem grande impacto na vida da mulher.

Mesmo com os avanços tecnológicos, o câncer ainda apresenta forte impacto emocional e social na vida das mulheres e seus familiares, medida em que coloca como uma possibilidade da finitude. Isso transforma a vida da mulher para sempre. As que processam essa transformação ampliam suas chances de convivência, controle do câncer e sobrevida.

Após as reflexões aqui produzidas sobre a importância dos fatores socioafetivos no tratamento do câncer de mama para a paciente e sua família e diante da complexidade que envolve o atendimento interdisciplinar, esperamos ter podido evidenciar como, tanto para a paciente, quanto para a família, os sentimentos para lidarem com o diagnóstico e 
com o tratamento são profundos e demandam compreensão e orientações de toda a equipe para que todos possam lidar com as mudanças que ocorreram nesses processos.

É nesse sentido que essa reflexão reconhece que todos precisarão de apoio socioassistencial, suporte emocional para seus sentimentos e para traçarem planos de enfrentamento da doença e para o futuro.

O acesso precoce ao sistema de rastreamento do câncer de mama e ao tratamento pelo SUS tem funcionado na reversão das expectativas de morte certa. Os maiores problemas ainda estão na detecção tardia dos tumores e no tempo de espera para o atendimento de alta complexidade. A fragmentação das ações evidencia ainda a presença de fragilidades a serem superadas.

O Serviço Social tem se revelado importante na efetivação do direito ao atendimento integral ao acompanhar a paciente durante todo o processo de tratamento, à medida que desenvolve ações de orientação à paciente, considerando, não só a necessidade da totalidade da atenção, como também a necessidade de se observar a transversalidade das políticas públicas, em especial as da seguridade social, assegurando o cuidado conforme determinações da Lei $8080 / 90$ do SUS e assegurando os direitos sociais.

A família tem sido considerada fundamental no enfretamento da doença, podendo contribuir para a melhoria ou para o agravamento do tratamento. O Serviço Social precisa ter clareza dos novos arranjos familiares para mobilizar os membros que a paciente considera como a sua família no intuito de contribuir na melhoria dos aspectos emocionais, rotina doméstica e sobrevivência financeira das pacientes, aliviando o excesso de responsabilidades na dinâmica familiar.

O excesso de responsabilidades pode ser um agravante do adoecimento, sobretudo se elas participarem do provimento econômico. O que pode vir a causar transtornos e suscitarem reações adversas em membros da família, que precisarão ser acompanhados de perto, sobretudo, em relação àqueles aspectos que podem repercutir sobre a recuperação da paciente.

Enfim, para que se adotem boas práticas, torna-se necessário que se preserve ou se construa uma boa comunicação familiar. Todas as possibilidades precisam ser problematizadas com todos os membros, com total participação da paciente. Nesse 
processo, é recomendável deixar claro que a paciente pode estar temporariamente limitada, porém, jamais incapacitada; que sofrerá limitações, mas que poderá contornálas, encontrando novas adequações à vida.

\section{Referências}

ALMEIDA, S. B. A trajetória de mulheres com câncer de mama: uma proposta de estudo sobre a prática avaliativa de integralidade nos municípios de Volta Redonda. Dissertação (Mestrado em Saúde Coletiva) , Rio de Janeiro: Universidade do Estado do Rio de Janeiro, Instituto de Medicina Social, 2009.

BIFFI, R.; MAMEDE, M.V. Percepção do funcionamento familiar entre familiares de mulheres sobreviventes ao câncer de mama: diferenças de gênero. São Paulo: Revista Latino-americana de Enfermagem, v. 18, n.2, mar.abr 2010. Acesso em 10 dez de 2010. Disponível em: <http://www.scielo.br/cgi-bin/wxis.exe/iah/>.

BRASIL. Ministério da Saúde. Política nacional de atenção integral à saúde da mulher. Brasília, 2004 . Política nacional de atenção oncológica. Brasília: Ministério da Saúde, 2005. . Secretaria de Atenção à Saúde. Coordenação de Prevenção e Vigilância. Instituto Nacional do Câncer. Situação do câncer no Brasil. Brasília, 2006.

. Secretaria de Atenção à Saúde. Coordenação de Prevenção e Vigilância. Departamento de Ações Programáticas Estratégicas. Política Nacional de Atenção Integral à Saúde da Mulher: princípios e diretrizes. Brasília, 2009.

BRITO, C.; PORTELA, M.; VASCONCELLOS, M. T. L. Sobrevida de mulheres tratadas por câncer de mama no estado do Rio de Janeiro. Revista Saúde Pública, São Paulo, v. 43, n. 3, p. 481-489, 2009.

COMIN, F. S.; SANTOS, M. A.; SOUZA, L. V. Vivências e discursos de mulheres mastectomizadas: negociações e desafios do câncer de mama. Estudos de psicologia, Campinas, v. 14, n. 1, p. 41-50, jan./abr. 2009. Acesso em: 3 fev 2011. Disponível em: <http://www.scielo.br/>.

DUARTE, T. P.; ANDRADE, A. N. Enfrentando a mastectomia: análise dos relatos de mulheres mastectomizadas sobre questões ligadas à sexualidade. Estudos de Psicologia, Campinas, v. 8, n. 1, p. 155-163, 2003.

FEDERAÇÃO BRASILEIRA DE INSTITUIÇÕES FILANTRÓPICAS DE APOIO À SAÚDE DA MAMA FEMAMA. Site: < http://www.femama.org.br/novo/>, 2012. 
FERRARI, C. L. S.; HERZBERG, V. Tenho câncer e agora? enfrentando o câncer sem medos ou fantasias. São Paulo: Sociedade Brasileira de Oncologia Clínica, 1997. Disponível em: <http://www.sboc.org.br>. Acesso em: 3 fev. 2011.

FRANCO, M. H. P. A família em pisco-oncologia. In: CARVALHO, V. A. (Org.). Temas de psico-oncologia. São Paulo: Summus, 2008. p. 358-361.

GENTILLI, R. M. L. Representações e práticas: identidade e processo de trabalho profissional no serviço social. 2. ed. São Paulo: Veras, 2006.

GUARINGUE, C.A.P. Assistencia social no serviço de tratamento oncológico. Acesso em 10 de fevereiro de 2010. Disponível em: http://www.ispon.com.br/?p=2222010

MACIEIRA, R. C.; LIBERATO, R. P. Espiritualidade no enfrentamento do câncer. In: CARVALHO, V. A. (Org.). Temas de psico-oncologia. São Paulo: Summus, 2008. p. 414-431.

MESSA, A. A. A. O impacto da doença crônica na família. 2003. Disponível em: <http://www.psicologia.org.br> Acesso em: 20 mar. 2011.

MILBRATH, V. M. et al . Integralidade e acessibilidade no cuidado à criança portadora de paralisia cerebral. Acta Paulista de Enfermagem, São Paulo, v. 22, n. 6, p. 755-60, 2009.

NETTINA, S. M. Prática de enfermagem. 7. ed. Rio de Janeiro: Guanabara Koogam, 2003.

ORGANIZAÇÃO MUNDIAL DA SAÚDE. Organização Pan-Americana de Saúde. Diretrizes internacionais para a saúde da mama e controle do câncer (Sinopse). Câncer, New Jersey, v. 113, n. 8, out. 2008. Disponível em: <http://new.paho.org>. Acesso em: 12 ago. 2011.

ONCOGUIA. O portal do paciente com câncer2011.. Acesso em: 12 ago. 2011. Disponível em: <http://www.oncoguia.com.br>.

RIBEIRO, E. M. P. C. O paciente terminal e a família. In: CARVALHO, M. M. M. J. Introdução a psicooncologia. São Paulo: Psy II, 1994. p. 197-217.

RODRIGUES, R. A. Direitos fundamentais na constituição de 1988. Porto Alegre: Núria Fabris, 2008.

ROLLAND, J.S. In: SILVA, N.C. Como o câncer (des) estrutura a família. 2001. Dissertação de Mestrado em Família. Instituto João Paulo II. Rio de Janeiro: INCA, 2001.

SIMONTON, S. M. A família e a cura: o método Simonton para famílias que enfrentam uma doença. São Paulo: Simmus, 1991.

SPINK, M. J. Psicologia social e saúde: práticas, saberes e sentidos. Petrópolis: Vozes, 2003.

TEIXEIRA, L. A.; FONSECA, C. O. (Coord.). De doença desconhecida a problema de saúde pública: o INCA e o controle do câncer no Brasil. Rio de Janeiro Ministério da Saúde/ FIOCRUZ/INCA, 2007. Disponível em: < http://www.inca.gov.br>. Acesso em: 3 fev. 2011. 
VENÂNCIO, J. L. A importância da atuação do psicólogo no tratamento de mulheres com câncer de mama. Rio de Janeiro: Revista Cancerologia, 2004.

XAVIER, B. B.; GENTILLI, R. M. L. Integralidade da atenção à saúde da mulher e o câncer de mama. In: CONGRESSO BRASILEIRO DE ASSISTENTES SOCIAIS, 13., 2010, Brasília. Anais... Brasília, 2010.

XAVIER, B. B. Fatores socioafetivos e tratamento de câncer de mama. 2011. Dissertação (Mestrado em Enfermagem) - Escola Superior de Ciências da santa Casa de Misericórdia de Vitória (EMESCAM), Vitória.

Recebido em: 16/02/2012

Aprovado em: 12/05/2012 